\title{
Evaluation of the Efficacy of $1 \%$ Alendronate Gel as Adjunctive Treatment in Class II Furcation Defects (Clinical, Radiographic and Biochemical Study)
}

\author{
Dalia H. Abd Elhafeez ${ }^{1}$, Mohamed F. Edrees ${ }^{1}$, Ahmed H. Gaber ${ }^{2}$
}

Codex : 11/2021/04

Aadj@azhar.edu.eg

\section{KEYWORDS}

Alendronate gel, root planing, class II furcation, Adjunctive Treatment, RANKL level.

1. Department of Oral Medicine, Periodontology, Oral Diagnosis and Dental Radiology, Faculty of dental medicine, (Assiut, boys), Al-Azhar University, Egypt.

2. Department of Oral Pathology, Faculty of dental medicine, (Assiut, boys), Al-Azhar University, Egypt.

* Corresponding Author e-mail: hanygobran.9@azhar.edu.eg

\begin{abstract}
Aim: This study was designed to evaluate the efficacy of $1 \%$ alendronate gel as an adjunctive therapy to scaling and root planing in the treatment of class II furcation defects. Subjects and method: Twenty-six patients with mandibular class II furcation involvement were selected from the out-patient clinic, Oral Medicine and Periodontology Department, Faculty of Dentistry, Al-Azhar University, Assiut Branch. They were divided into two equal groups. Group I received conventional periodontal therapy alone, while group II received conventional periodontal therapy combined with intra-furcal application of $1 \%$ alendronate gel as adjunctive therapy. All patients were evaluated clinically, radiographically as well as for RANKL level in GCF at base line, 3 and 6 months. Results: Both groups showed a high significant difference between base line and 6 months in all clinical parameters (PI, GI, VPD, CAL and HPD), radiographic parameters (bone density) and RANKL level in GCF. There was a statistical significant difference to group II when compared to group I in VPD and HPD at 6 months only and in CAL, bone density and RANKL level at 3 and 6 months. Conclusion: intra-furcal application of $1 \%$ Alendronate gel seemed an attractive effect as adjunctive therapy in improving the clinical, radiographic parameters and RANKL level in GCF in the treatment of class II furcation defects
\end{abstract}

\section{INTRODUCTION}

Periodontitis is an inflammatory lesion resulting from the interaction between periodontal biofilm-associated microorganisms and the host response mechanisms and characterized by soft tissue destruction and bone resorption in the supporting apparatus of the tooth. ${ }^{(1)}$ This destruction resulting in attachment loss sufficient enough to affect the furcation of multi-rooted teeth $\&$ this is one of the most serious sequels of periodontitis. ${ }^{(2)}$

The key cytokine system that regulates bone remodeling process is dependent on the receptor activator of nuclear factor-kappa B ligand (RANKL) and osteoprotegerin (OPG) balance. RANKL stimulates the 
osteoclastic activity and differentiation and inhibits the osteoclast apoptosis. It binds to osteoclast progenitor cells inducing changes in their gene expression that modulate the formation of bone resorbing osteoclasts. ${ }^{(3)}$

Non-surgical periodontal treatment has been proven to reduce a significant amount of periodontal disease manifestations. ${ }^{(4)}$ As the furcation is an area of complex anatomic morphology that may be difficult to be debrided by routine periodontal instrumentation, the effectiveness of periodontal debridement may be reduced with increased pocket depth, furcation involvement, and presence of anatomical variations like root curvatures which can make it difficult for scaling and root planing (SRP) to completely remove bacterial deposits and biofilms from the root surface. ${ }^{(5,6)}$

Accordingly, host modulatory therapy (HMT) has emerged as a new concept for the treatment of periodontal diseases aiming to reduce tissue destruction and stabilize or even regenerate the periodontium by modifying or down-regulating the destructive aspects of the host response and upregulating the protective or regenerative responses. HMT comprises systemically or locally delivered pharmaceuticals. ${ }^{(7,8)}$

Bisphosphonates (BPs) is a group of bone metabolism mediators that has affinity to bind to hydroxyapatite crystals and prevent their dissolution and has ability to increase osteoblast differentiation and inhibit osteoclast recruitment and activity. ${ }^{(9)}$ Alendronate (ALN) is a commonly-used BPs, and is proposed to have osteo-stimulative properties in vivo and in vitro, as shown by an increase in the matrix formation. It acts as a potent inhibitor of bone resorption that has been postulated to be of therapeutic value as a supportive therapy in management of periodontitis. ${ }^{(10)}$

So, the primary research question in the present study was that: upon the proved efficacy of ALN as an inhibitor to osteoclastic chemotaxis and activity in addition to its bone forming potentiality, does application of ALN gel 1\% as adjunctive to scaling and root planing in class II furcation defects, can be enhance the treatment outcomes?

\section{PATIENTS AND METHOD}

Patients: twenty-six patients of both sex (12 females and 14 males ranged in age from 45-62 years) with class II mandibular furcation involvement. All patients were selected from those attending at the out-patient clinic, Oral Medicine and Periodontology Department, Faculty of Dentistry, Al-Azhar University, Assiut. All patients were thoroughly informed of the nature, potential risks and benefits of their participation in the study and signed their informed consent documents. The study protocol was approved by the ethical committee, Faculty of Dentistry, Al-Azhar University, Assiut.

Inclusion criteria: The patients were free from any systemic diseases according to the criteria of Cornell Medical index and its modification, ${ }^{(11)}$ with class II furcation involvement in asymptomatic vital mandibular molars according to Hamp et al. classification, ${ }^{(12)}$ with $(\mathrm{HPD}) \geq 3 \mathrm{~mm}$ but not encompassing the total width of the furcation area.

Exclusion criteria: Uncooperative, pregnant, lactating, smokers patients, who received antibiotics, non-steroidal, anti-inflammatory or vitamin supplements during at least 3 months, patients subjected to previous periodontal therapy during at least 6 months or received systemic drugs that modifying the bone remodeling at least 12 months prior to beginning of the study.

Patients grouping: The selected patients were divided randomly using flipping coins into two equal groups into

Group I: Included 13 patients with class II mandibular furcation involvement received conventional periodontal therapy (scaling and root planing) alone. 
Group II: included 13 patients with class II mandibular furcation involvement received conventional periodontal therapy (scaling and root planing) combined with intra-furcation application of $1 \%$ Alendronate gel.

Periodontal treatment: All patients received phase 1 periodontal therapy and full mouth scaling and root planing performed in three or four visits without adjunct disinfectants.

In patients of group II only and immediately after the last session, the selected teeth were isolated by cotton rolls for intra-furcation application of $1 \%$ ALN gel.

Formulation of $1 \%$ ALN gel: It was prepared as described by Reddy, et al. (2005) ${ }^{(13)}$ with ALN powder ${ }^{*}$ was dissolved in a required amount of distilled water to achieve $1 \%$ ALN concentration. A weighed quantity of carbopol 934P $(2 \% \mathrm{w} / \mathrm{w})$ was taken and added to the distilled water. The mixture was gradually stirred and carbopol was allowed to soak for $2 \mathrm{~h} .1 \%$ triethanolamine was added to neutralize the carbopol solution and to form the gel. The $\mathrm{pH}$ was adjusted to 6.8. Finally, the required amount of methylparaben $(0.1 \%)$ and propylparaben $(0.05 \%)$ were dissolved in ethanol and added to the gel.

Clinical evaluation: The patients of both groups were evaluated clinically at base line, 3 and 6 months using the following parameters plaque index (PI), gingival index (GI), vertical probing depth (VPD), clinical attachment level (CAL) and horizontal probing depth (HPD).

Radiographic evaluation: A standardized periapical radiograph was taken using long cone parallel technique at base line, 3 and 6 months. The region of interest (ROI) was traced and outlined at the furcation area from the furcation fornix to the base of the defect and laterally between the two root surfaces. The bone density for ROI was calculated in pixels using $\mathrm{J}$ image program.
Biochemical evaluation: Gingival crevicular fluid (GCF) samples were obtained from the site of furcation involvement at baseline, 3 and 6 months. Sterilized paper point size \#30 was carefully inserted to the maximum depth and held in position for 30 seconds. The paper point which contaminated with blood or saliva was excluded. The collected GCF was immediately transferred to an Eppendorf tube containing phosphate buffer solution and transported to the laboratory. Samples were assayed for RANKL level using commercially available enzyme-linked immunosorbent assay (ELISA) according to the manufacturer's instructions.

\section{Statistical analysis}

The mean and standard deviation values were calculated for each group in each test. The significance level was set at $\mathrm{P} \leq 0.05$. Statistical analysis was performed with IBM ${ }^{\circledR}$ SPSS Statistics Version 20 for Windows.

\section{RESULTS}

Twenty-six patients had class II mandibular furcation involvement with $\mathrm{HPD} \geq 3 \mathrm{~mm}$ were selected to be included in the present study. The patients were divided randomly into two groups; group I received SRP only and group II received SRP combined with intra-furcation application 1\%ALN gel.

Means of clinical parameters, bone density and RANKL level as well as $p$-values between the groups were illustrated in table (1).

\section{Plaque index (PI)}

- There was a statistically significant difference between baseline, $3 \mathrm{~m}$ and $6 \mathrm{~m}$ in both groups where $(p<0.001)$.

- There was no statistically significant difference between group I and group II at base line, 3 and 6 months where $(p=0.059),(p=0.205),(p=0.302)$ respectively.

\footnotetext{
* Alfa Aesar, Thermo Fisher Scientific, Germany
} 


\section{Gingival index (GI)}

- A statistically significant difference between baseline, $3 \mathrm{~m}$ and $6 \mathrm{~m}$ was found in both groups where $(p<0.001)$.

- There was a statistically significant difference between group I and group II at 3 months only where $(p=0.001)$.

\section{Vertical probing depth (VPD)}

- There was a statistically significant difference between baseline, $3 \mathrm{~m}$ and $6 \mathrm{~m}$ in both groups where $(p<0.001)$.

- No statistically significant difference for the vertical probing depth between group I and group II at base line and 3 months while there was a statistically significant difference at 6 months where $(p=0.150),(p=0.062)$ and $(p=0.005)$ respectively.

\section{Clinical attachment level (CAL)}

- There was a statistically significant difference between baseline, $3 \mathrm{~m}$ and $6 \mathrm{~m}$ in both groups where $(p<0.001)$.

- There was a statistically significant difference between group I and group II at 3 and 6months where $(p=0.014)$ and $(p=0.004)$ respectively.

\section{Horizontal probing depth (HPD)}

- There was a statistically significant difference between baseline, $3 \mathrm{~m}$ and $6 \mathrm{~m}$ in both groups where $(p<0.001)$.

- There was a statistically significant difference between group I and group II at 6monthsonly where $(p<0.001)$.

\section{Bone density (BD)}

- There was a statistically significant difference between baseline, $3 \mathrm{~m}$ and $6 \mathrm{~m}$ in both groups where $(p<0.001)$ figure $(1)$.

- There was a statistically significant difference between group I and group II at 3 and 6months where $(p=0.041)$ and $(p=0.003)$ respectively.

\section{RANKL level}

- There was a statistically significant difference between baseline, $3 \mathrm{~m}$ and $6 \mathrm{~m}$ in both groups where $(p<0.001)$.

- There was a statistically significant difference between group I and group II at 3 and 6months where $(p=0.010)$ and $(p=0.006)$ respectively.

Lastly, there was a positive correlation between RANKL and all the clinical parameters, but there was a negative correlation between RANKL and bone density.
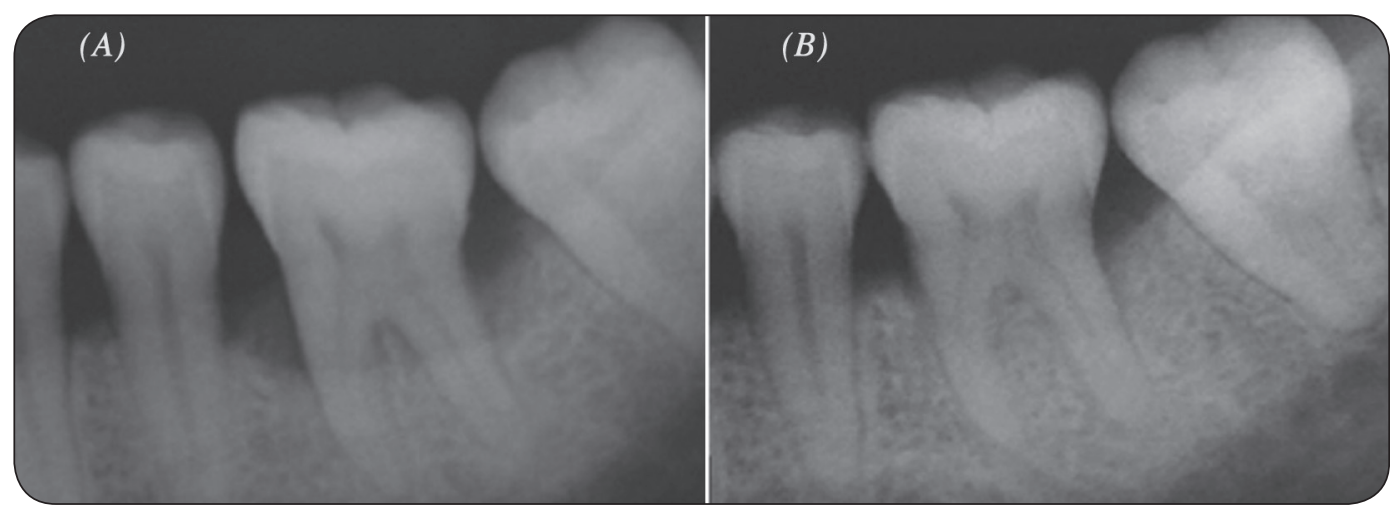

Fig. (1) Radiographic difference in patient of group II, a: before treatment and b: after treatment 
Table (1) means $\pm S D$ and p-value of the clinical parameters, bone density and RANKL level between the both groups.

\begin{tabular}{|c|c|c|c|c|c|c|}
\hline \multirow[b]{2}{*}{ Parameters } & \multicolumn{2}{|c|}{ Group I } & \multicolumn{3}{|c|}{ Group II } & \multirow{2}{*}{$\begin{array}{c}\text { p-value between } \\
\text { the two groups } \\
\text { at } 6 \mathrm{~m}\end{array}$} \\
\hline & $\begin{array}{c}\text { Mean } \pm \text { SD at } \\
\text { baseline }\end{array}$ & Mean $\pm \mathrm{SD}$ at $6 \mathrm{~m}$ & $\begin{array}{r}\text { Mea } \\
\mathrm{b}\end{array}$ & ne at & Mean $\pm \mathrm{SD}$ at $6 \mathrm{~m}$ & \\
\hline PI & $2.77 \pm 0.190$ & $0.44 \pm 0.150$ & 2.6 & 240 & $0.39 \pm 0.165$ & $\mathrm{P}=0.302^{\mathrm{ns}}$ \\
\hline GI & $2.37 \pm 0.263$ & $0.31 \pm 0.208$ & $2.54 \pm$ & 0.247 & $0.21 \pm 0.138$ & $\mathrm{P}=0.138^{\mathrm{ns}}$ \\
\hline VPD & $4.46 \pm 0.345$ & $3.05 \pm 0.218$ & $4.64 \pm$ & 0.269 & $2.61 \pm 0.477$ & $\mathrm{P}=0.005^{*}$ \\
\hline CAL & $3.22 \pm 0.215$ & $2.25 \pm 0.247$ & $3.26 \pm$ & 0.233 & $1.95 \pm 0.233$ & $\mathrm{P}=0.004^{*}$ \\
\hline HPD & $4.77 \pm 0.439$ & $2.69 \pm 0.630$ & 4.6 & 506 & $1.08 \pm 0.641$ & $\mathrm{P}<0.001^{*}$ \\
\hline BD & $87.0 \pm 5.40$ & $117.0 \pm 5.57$ & $87.4 \pm$ & 5.90 & $125.3 \pm 7.31$ & $\mathrm{P}=0.003^{*}$ \\
\hline RANKL & $290.2 \pm 32.0$ & $214.9 \pm 26.4$ & 286 & 5.5 & $189.9 \pm 13.5$ & $\mathrm{P}=0.006^{*}$ \\
\hline
\end{tabular}

*; significant $(p<0.05)$, ns; non-significant $(p>0.05)$

\section{DISCUSSION}

Periodontitis is an inflammatory condition characterized by the occurrence of tooth supporting tissue destruction with an episodic nature and disease progression is often determined by the loss of attachment level and/or alveolar bone. ${ }^{(14)}$ In multi-rooted teeth, the severity of attachment loss is determined by the degree of furcation involvement both horizontally toward the interior of the furcation and vertically along the root. ${ }^{(15)}$

SRP is often sufficient to suppress bacterial pathogens, thereby attaining periodontal health. Benefits attributed to LDD are raising drug concentration directly in the action site, preventing systemic side effects, less treatment time, more conservative and decreased root sensitivity. ${ }^{(16)}$

Alendronate (ALN) is a third-generation nitrogen BPs. It favors osteoclast apoptosis and inhibits osteoclast differentiation during the maturation process. ${ }^{(17)}$ The action of ALN on bone would appear to be related to its capacity to inhibit bone resorption. ${ }^{(18)}$

The present study was designed to evaluate the efficacy of $1 \%$ ALN gel as adjunct to SRP in the treatment of Class II furcation defects.
In accordance to Bernardo et al (2017) ${ }^{(19)}$ and Ipshita et al. (2018), ${ }^{(20)}$ the results of the present study showed a significant difference in both plaque index and gingival index after 3 and 6 months when compared to base line in the two groups which may be due to the decrease of bacterial amount with subsequent reduced inflammation by supportive periodontal therapy.

VPD in both groups showed a statistical significance at 3 and 6 months when compared to base line. In addition, there was a statistical significant difference in VPD in group II after 6 months when compared to group I. These results were similar to Bernardo et al. (2017). ${ }^{(19)}$ While Kanoriya et al. (2016) ${ }^{(21)}$ showed more reduction in VPD because a mixture of PRF with ALN was used.

The present study showed a significant difference in CAL in both groups at 3 and 6 months when compared to base line and the amount of reduction in CAL after 6 months was high in Alendronate group in agreement to Ipshita et al. (2018) ${ }^{(20)}$ who gained more reduction in CAL.

After 6 months in group II, the amount of reduction in HPD shifted all the cases from class II to class I furcation involvement. There was a 
statistical significant difference in HPD in group II after 6 months when compared to group I. These results were similar to Ipshita et al. (2018) ${ }^{(20)}$, but higher than that obtained by Sharma et al (2017) ${ }^{(22)}$, who acted on smokers patients.

Bostanci et al. (2007) ${ }^{(23)}$ reported a reduction in GCF level of RANKL after periodontal treatment and positive correlation between the RANKL level and PPD in patients with periodontitis which is in agreement with the present findings. The results of the present study also exhibited a significant difference in RANKL level in group II after 3 and 6 months when compared to group I.

Bone density showed a statistically significant difference between base line when compared to 3 and 6 months. In addition, there was a statistically significant difference at 3 and 6 months in group II when compared to group I. These results are in agreement to Pradeep et al. (2016) (24) and Sheokanda et al. (2018) ${ }^{(25)}$ who reported that topical application of alendronate showed a gain in bone density and improved bone mass after $6 \mathrm{~m}$ observational period.

\section{CONCLUSION}

Local application of ALN gel 1\% seemed an attractive effect as adjunctive therapy in improving both vertical and horizontal probing depth as well as CAL in management of class II mandibular furcation involvement. ALN exhibited an osteogenic efficacy through the recovery of bone density of the furcal area. RANKL can be considered a good bone biomarker to evaluate treatment outcomes through the strong correlations with clinical and radiographic parameters.

\section{REFERENCES}

1. Taubman MA, Kawai $\mathrm{T} \&$ Han $\mathrm{X}$. The new concept of periodontal disease pathogenesis requires new and novel therapeutic strategies. J Clin Perio.2007; 34:367-69.
2. Graves D. Cytokines that promote periodontal tissue destruction. J Perio. 2008; 79:1585- 91.

3. Hsu H, Lacey D L, Dunstan CR, Solovyev I, Colombero A, Timms E, et al. Tumor necrosis factor receptor family member RANK mediates osteoclast differentiation and activation induced by osteoprotegerin ligand. Proc Natl Acad Sci USA.1999; 96:3540-45.

4. De Sanctis M \& Murphy KG. The role of resective periodontal surgery in the treatment of furcation defects. $\mathrm{J}$ Perio 2000. 2000; 22:154-68.

5. Wennström JL, Dahlén G \& Ramberg P. Subgingival debridement of periodontal pockets by air polishing in comparison with ultrasonic instrumentation during maintenance therapy. J Clin Perio. 2011; 38(9):820-27.

6. Heitz-Mayfield LJ \& Lang NP. Surgical and nonsurgical periodontal therapy. Learned and unlearned concepts. J Perio 2000. 2013; 62:218-31.

7. Bhatavadekar NB \& Williams RC. New directions in host modulation for the management of periodontal disease. $\mathrm{J}$ Clin Perio. 2009; 36:124-26.

8. Salvi GE \& Lang NP. Host response modulation in the management of periodontal diseases. J Clin Perio. 2005; 32(6):108-29.

9. Adami S, Zamberlan N, Mian M, Dorizzi R, Rossini M, Braga B, et al. Duration of the effects of intravenous alendronate in postmenopausal women and in patients with primary hyperparathyroidism and Paget's disease of bone. Bon Min. 1994; 25(2):75-82.

10. Tenenbaum HC, Torontali M \& Sukhu B. Effects of bisphosphonates and inorganic pyrophosphate on osteogenesis in vitro. Bon. 1992; 13(3):249-55.

11. Brodman K, Erdmann AJ \& Wolff HG. Cornell Medical Index Health Questionnaire (manual). New York, NY: Cornell University Medical College, 1956.

12. Hamp SE, Nyman S \& Lindhe J. Periodontal treatment of multirooted teeth. Results after 5 years. J Clin Perio. 1975; 2:126-30

13. Reddy GT, Kumar PM \& Veena KM. Formulation and evaluation of alendronate sodium gel for the treatment of bone resorptive lesions in periodontitis. Dru Deliv. 2005; $12: 217-22$

14. Hernandez M, Dutzan N, Garcia S, Hostnich J, Abusleme L, Dezerega A, et al. Host pathogen interactions in progressive chronic periodontitis. J Dent Res. 2011; 90(10):1164-70. 
15. Waerhaug J. The furcation problem. Etiology, pathogenesis, diagnosis, therapy and prognosis. J Clin Perio.1980; 7:73-95.

16. Greenstein G \& Polson A. The role of local drug delivery in the management of periodontal diseases: A comprehensive review. J Perio. 1998; 69:507-20.

17. Chacon GE, Stine EA, Larsen PE, Beck Fm \& McGlumphy EA. Effect of alendronate on endosseous implant integration: an in vivo study in rabbits. J Ora Maxillofac Surg. 2006; 64:1005-09.

18. Udagawa N, Takahashi N, Jimi E, Matsuzaki K, Tsurukai T, Itoh $\mathrm{K}$, et al. Osteoblasts/stromal cells stimulate osteoclast activation through expression of osteoclast differentiation factor/RANKL but not macrophage colony-stimulating factor. Bon. 1999; 25:517-23.

19. Bernardo CD, Dutra Olivera AM, Dutra Olivera PA, Manzi FR, Cortelli SC, Cota LO, et al. Effect of $1 \%$ sodium alendronate in the non-surgical treatment of periodontal intraosseous defects: a 6-month clinical trial. J Appl Oral Sci. 2017; 25:310-17.

20. Ipshita S, Kurian IG, Dileep P, Kumar S, Singh P \& Pradeep AR. One percent alendronate and aloe vera gel local host modulating agents in chronic periodontitis patients with class II furcation defects: A randomized, controlled clinical trial. J Inv Clin Dent. 2018; 12334:1-7.
21. Kanoriya D, Pradeep AR, Singhal S, Garg V\& Guruprasad CN. Synergistic Approach Using Platelet-Rich Fibrin and 1\% Alendronate for Intrabony Defect Treatment in Chronic Periodontitis: A Randomized Clinical Trial. J Perio. 2016; 87:1427-34.

22. Sharma A, Raman A, Pradeep AR. Role of $1 \%$ alendronate gel as adjunct to mechanical therapy in the treatment of chronic periodontitis among smokers. J appl ora sci.2017; 25:243-49.

23. Bostanci N, Ilgenli T, Emingil G, Afacan B, Han B, Töz H, et al. Gingival crevicular fluid levels of RANKL and OPG in periodontal diseases: Implications of their relative ratio. J Clin Perio. 2007; 34:370-76.

24. Pradeep AR, Karvekar S, Kanika N, Patnaik K, Raju A \& Priyanka SP. Rosuvastatin $1.2 \mathrm{mg}$ in Situ Gel Combined with 1:1 Mixture of Autologous Platelet-Rich Fibrin and Porous Hydroxyapatite Bone Graft in Surgical Treatment of Mandibular Class II Furcation Defects: A Randomized Clinical Control Trial. J Perio.2016; 87:5-13.

25. Sheokanda V, Chadhab VS \& Palwankarb P. The comparative evaluation of $1 \%$ alendronate gel as local drug delivery system in chronic periodontitis in smokers and non-smokers: Randomized clinical trial. J Ora Biol Craniofac Res.2019; 9(2):198-203. 
90

مجلة أسيوط لطب الأسنان
النشر الرسمي لكلية طب الأسنان جامعة الأزهر أسيوط الكاية

مصر

\section{تقييم فاعلية \% 1 الندرونات جيل كعلاج مساعد للخلل العظمصي بين الجذور من الدرجة الثاندانية (دراسة اكلينيكية وبالاشعة وبالكيمياء الحيوية)}

داليا حامد عبد الحفيظ1 ، محمد فؤاد ادريس1 ، أحمد حسين جابر2

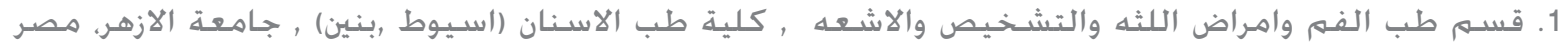

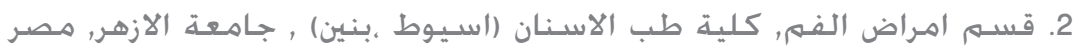

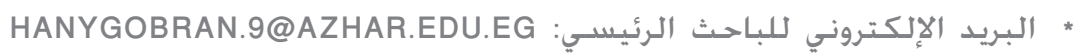

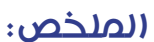

الهدف: أجريت الدراستة لتقييم التأثير الاكلينكي وبالأشعة ومعمليا لاستخدام مادة الالندرونات بتركيز 1\% على هيئة جل على الخلل

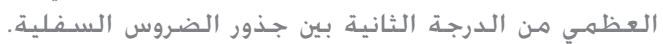

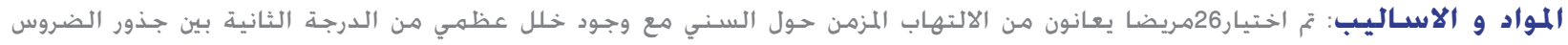

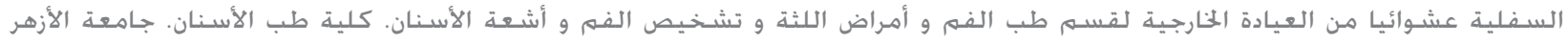

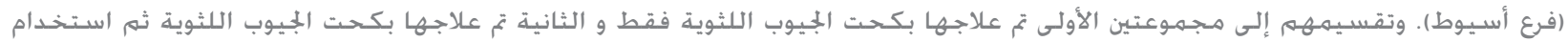
جل الالندرونات بتركيز 1\% موضعيا.

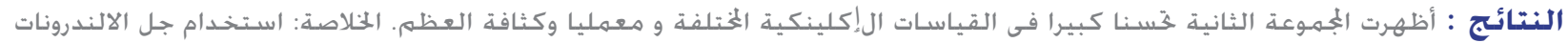

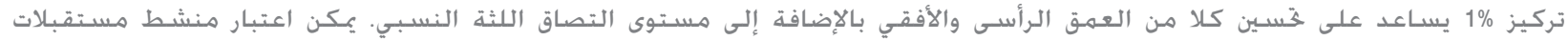

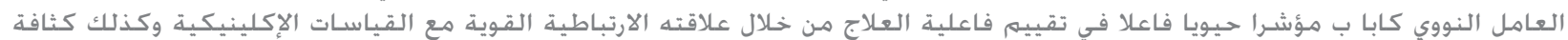

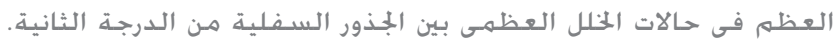

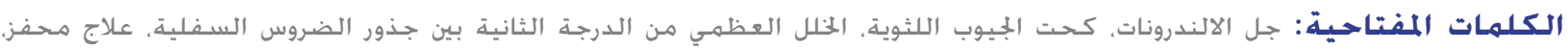
القياسـات الاكلينكيه. المفياحية. 